\title{
Ectasia risk factors in refractive surgery
}

This article was published in the following Dove Press journal:

Clinical Ophthalmology

20 April 2016

Number of times this article has been viewed

\author{
Marcony R Santhiago' \\ Natalia T Giacomin' \\ David Smadja ${ }^{2}$ \\ Samir J Bechara'
}

'Department of Ophthalmology, Federal University of São Paulo, São Paulo, Brazil, ${ }^{2}$ Ophthalmology Department, Tel Aviv Sourasky Medical Center, Tel Aviv, Israel
Correspondence: Marcony R Santhiago Department of Ophthalmology, Instituto Central, Federal University of São Paulo, AV Dr Enéas de Carvalho Aguiar, 255, São Paulo, Brazil

Email marconysanthiago@hotmail.com
Abstract: This review outlines risk factors of post-laser in situ keratomileusis (LASIK) ectasia that can be detected preoperatively and presents a new metric to be considered in the detection of ectasia risk. Relevant factors in refractive surgery screening include the analysis of intrinsic biomechanical properties (information obtained from corneal topography/tomography and patient's age), as well as the analysis of alterable biomechanical properties (information obtained from the amount of tissue altered by surgery and the remaining load-bearing tissue). Corneal topography patterns of placido disk seem to play a pivotal role as a surrogate of corneal strength, and abnormal corneal topography remains to be the most important identifiable risk factor for ectasia. Information derived from tomography, such as pachymetric and epithelial maps as well as computational strategies, to help in the detection of keratoconus is additional and relevant. High percentage of tissue altered (PTA) is the most robust risk factor for ectasia after LASIK in patients with normal preoperative corneal topography. Compared to specific residual stromal bed (RSB) or central corneal thickness values, percentage of tissue altered likely provides a more individualized measure of biomechanical alteration because it considers the relationship between thickness, tissue altered through ablation and flap creation, and ultimate RSB thickness. Other recognized risk factors include low RSB, thin cornea, and high myopia. Age is also a very important risk factor and still remains as one of the most overlooked ones. A comprehensive screening approach with the Ectasia Risk Score System, which evaluates multiple risk factors simultaneously, is also a helpful tool in the screening strategy.

Keywords: ectasia, risk factor, refractive surgery, PTA

\section{Introduction}

Corneal ectasia is a sight-threatening complication of excimer laser refractive surgery characterized by progressive steepening and thinning of the cornea. Although its prevalence is theoretically low, estimated between $0.04 \%$ and $0.6 \%,{ }^{1}$ we believe that this problem is underestimated. Understanding, recognizing, and accepting its risk factors are crucial steps toward achieving a significant reduction in the occurrence of this adverse event. This review outlines risk factors of post-laser in situ keratomileusis (LASIK) ectasia that can be detected preoperatively and presents a new metric to be considered in the detection of ectasia risk.

\section{Concept of a risk factor}

The main purpose of assessing risk is not to determine who will or will not develop ectasia, but rather, based on stringent scientific analysis, to determine what group or groups of people present a higher chance of the event happening. ${ }^{1}$

There is a significant difference between the definitions of prevalence of factors in a group (which is related to how many people in that group present with the factor) and the influence of the factors on that group (which is related to something that can occur in that group when exposed to the factor). Analysis of prevalence is not sufficient to 
investigate a risk factor. An appropriate tool to investigate the association between a particular factor and an outcome is the odds ratio value.

\section{Ectasia after excimer laser refractive surgery}

Corneal ectasia after excimer laser refractive surgery most likely represents a disruption of biomechanical integrity and a subsequent reduction below the threshold required to maintain corneal shape and curvature. ${ }^{2-5}$

There are mainly three settings where this event could theoretically occur: 1) when a cornea already destined to manifest ectasia has surgery, which could be the case in patients who have not yet developed the first detectable topographic signs of an intrinsic corneal disease associated with fragility, such as keratoconus; ${ }^{6}$ 2) a preoperatively weak but clinically stable cornea that undergoes a surgery, which could be the case in eyes that present only subtle topographic or tomographic signs of abnormality, fellow eyes of eyes with frank keratoconus, and eyes that do not present specific criteria for a disease associated with biomechanical fragility but significantly deviates from what is expected in the normal population and, therefore, should be at least considered suspicious; $;^{7,8}$ or 3 ) when a relatively normal cornea is weakened below a safe threshold, creating biomechanical instability, which could be explained by the relative percentage contribution of the anterior stroma to the total corneal strength, which is modified after excimer laser refractive surgery, associated with a high percentage of tissue altered (PTA). ${ }^{9-12}$

Therefore, relevant factors in refractive surgery screening include the analysis of intrinsic biomechanical properties, an information obtained from corneal topography/tomography and patient's age, as well as the analysis of alterable biomechanical properties, an information obtained from the amount of tissue altered by surgery and the remaining load-bearing tissue. $9,13,14$

\section{Ectasia risk factors}

\section{Information obtained from Placido disk corneal topography}

Placido disk-based automated corneal topography was introduced in the late 1980s and remains until now as the standard of care for preoperative patient screening before keratorefractive surgery. ${ }^{15}$ The most important warning sign for ectasia risk is still abnormal corneal topography. Its principle is based on the computerized analysis of corneal images obtained from the reflection of a Placido disk onto the corneal surface and has been found to be highly sensitive in the detection of early keratoconus, prior to loss of corrected visual acuity and biomicroscopic findings. ${ }^{16,17}$ Klyce and Wilson ${ }^{15,18}$ first published about the normal and abnormal patterns of corneal topography and that the emerging interest in laser keratorefractive surgery along with the onset of post-LASIK ectasia cases associated with early keratoconus has led to the development of several literature-validated keratoconus detection schemes. ${ }^{16,17}$

It is very important to remind the readers that the correct analysis of Placido disk-based topography starts with the interpretation of its pattern and, more importantly, how much it deviates from topographic maps obtained from the normal population. ${ }^{15,17-21}$ A better understanding of the most common, repeated, or the "standard deviation" pattern of the normal population is a paramount step for any refractive surgeon. Lacking that essential knowledge significantly increases the risk of misinterpretation. Subtle abnormal topographic patterns are among the most overlooked risk factors in refractive surgery. An altered topographic pattern represents a biomechanically fragile structure, which means a higher risk of ectasia if surgery is performed and tissue is removed. ${ }^{4,22}$

Although some diseases are related to recognizable abnormal topographic patterns or altered indexes, especially when presenting the classic well-defined keratoconus (or any other ectatic disease) patterns, these are certainly not the only ways in which an abnormal status is presented. There are some subtle signs of corneal alterations in the intrinsic structure, and sometimes even obvious topographic signs of abnormality, that could have been misclassified with computational indexes because they are not classically related to keratoconus. ${ }^{9,22-27}$

There are indexes that have been widely used and implemented in most of the corneal topographers. Rabinowitz et al have proposed inferior-superior (I-S) ratio ${ }^{21}$ values and the keratometry, inferior-superior value, simulated astigmatism, and astigmatism (KISA) $\%$ index, ${ }^{28}$ which is a formula that combines the central keratometry power, the I-S value, the corneal-simulated astigmatism (SimCyl), and a representation of the irregular astigmatism (smallest angle between two steep radii subtracted from $180^{\circ}$ ). Maeda et al proposed the keratoconus prediction index, derived from a combination of indexes in an attempt to better differentiate eyes with keratoconus. ${ }^{29}$ The cone location and magnitude index, proposed by Mahmoud et al, is another promising tool with high sensitivity and specificity. ${ }^{30}$

However attractive these may be and though all these indexes are of great relevance to the refractive surgery field in making analyses more reproducible and comparable among 
physicians, the interpretation of a topography map goes far beyond the numbers and includes detailed analyses of the shape and topographic pattern. After the correct interpretation of the maps, an analysis that should always be bilateral, and assuming that the images were properly captured, considering the ocular surface and the technique, multiples of computationally derived keratoconus detection indexes are definitely useful, but these may only add to what has been determined by the topographic pattern and never subtract from what has been identified, even subtle signs of abnormality.

Recent studies ${ }^{7,23-27}$ have shown that subtle abnormal patterns that were not classically associated with keratoconus could still increase the chances of biomechanical instability, even after a refractive surgery that involves low values of PTA. Therefore, it is at least challenging to determine any safety limits in this particular group that includes less significant inferior steepening, any significant skewed radial axis with or without inferior steepening, or one diopter or more of inferior steepening in some areas but an I-S value of $<1.4,{ }^{7}$ betweeneye topographic asymmetry, even if neither eye's topographic pattern is in itself decidedly abnormal, and young patients with against-the-rule astigmatic patterns. ${ }^{24-26}$ Using these suspicious topographic patterns and relative asymmetry as a surrogate for corneal strength measurements, these findings signify that less tissue alteration was necessary to induce ectasia in eyes with less biomechanically stable corneas. ${ }^{7,23-27}$

\section{Information obtained with tomography}

While clinical keratoconus is reliably detected with Placido disk-based corneal topography and even sometimes at slitlamp examination, several indices and artificial intelligence methods have also been investigated by different available technologies, including scanning-slit, ${ }^{31}$ Scheimpflug, ${ }^{32,33}$ dual Scheimpflug, ${ }^{8,34}$ optical coherence tomography, ${ }^{35}$ and very high-frequency digital ultrasound, ${ }^{36}$ that ultimately analyze the anterior corneal curvature, posterior corneal surface, corneal thickness (central or relational), epithelial mapping, or biomechanical measurements.

Several corneal indices based on elevation, $, 3,31,37,38$ using different reference surfaces, ${ }^{34}$ thickness profiles, ${ }^{37,38}$ or wavefronts ${ }^{39}$ have been reported to improve the sensitivity of subclinical keratoconus detection. Smadja et a ${ }^{8}$ studied a new screening algorithm using dual Scheimpflug analyzer and showed an automated decision tree classifier that allows the detection of keratoconus and forme fruste with promising combination of sensitivity and specificity.

All these tools are widely available and have shown promise as adjuvant tools when screening refractive surgery candidates; however, none to date have proven to be more sensitive or reliable at detecting keratoconus suspect features than Placido imaging. ${ }^{40-42}$ Most quantified scoring approaches to date have found significant overlaps even between known control and abnormal populations.

\section{Percentage of tissue altered}

As previously mentioned, another important part of the screening process is the analysis of alterable biomechanical properties, through the amount of tissue altered by surgery and the remaining load-bearing tissue.

There is an integrated relationship between preoperative corneal thickness, ablation depth (AD), and flap thickness (FT) in determining the relative amount of biomechanical change that has occurred after a LASIK procedure. Santhiago et al coined the term, ${ }^{11}$ proposed it first, ${ }^{9}$ investigated and determined its association with ectasia, ${ }^{7-11}$ and tested and validated $^{7,10,11}$ a new metric, the PTA, that describes this interaction during excimer laser refractive surgery, which for LASIK can be described as PTA $=(\mathrm{FT}+\mathrm{AD}) /$ central corneal thickness (CCT) ${ }^{7,9-12}$

\section{Potential use of PTA in practice}

While most patients who have developed ectasia after LASIK have, in retrospect, had identifiable risk factors, particularly irregular topographic patterns, that placed them at higher risk for this complication, ectasia cases in patients with normal preoperative topography still remains a conundrum. In their studies, Santhiago et al ${ }^{9-11}$ provided evidence that a high value of PTA, especially $>40 \%$, is a relevant factor in the development of post-LASIK ectasia in eyes with normal preoperative Placido disk-based topography, and therefore, PTA should be taken into account as a screening parameter for refractive surgery candidates. This metric more accurately represents the risk of ectasia than the individual components that comprise it. ${ }^{7,9-11}$

According to the studies conducted by Santhiago et al, the risk of ectasia rapidly increases with a PTA value $>35 \%$ (with 100\% sensitivity) and peaks its maximum combination of sensitivity and specificity when $\geq 40 \%$. $^{9-11}$

Since the cohesive tensile strength is not uniform throughout the central corneal stroma and the one-third anterior region of the corneal stroma has significantly greater cohesive tensile strength, ${ }^{43-45}$ removing this relevant part of the stroma may induce corneal weakening in increasing proportions as the threshold of $35 \%$ or $40 \%$ is reached and crossed. ${ }^{7-11}$ As compared to specific residual stromal bed (RSB) or CCT values, PTA likely provides a more individualized measure of 
biomechanical alteration because it considers the relationship between thickness, tissue altered through ablation and flap creation, and ultimate RSB thickness.

\section{Association between PTA and ectasia in eyes with normal topography}

Our studies ${ }^{9-11}$ revealed that in eyes with normal preoperative topography, PTA had higher prevalence, higher odds ratio, and higher predictive capabilities for ectasia risk than moderate to high Ectasia Risk Score System (ERSS) values, $\mathrm{RSB}, \mathrm{CCT}$, high myopia, AD, and age. PTA $\geq 40$ was a more robust indicator of risk than other variables in patients with normal preoperative topography, being even more sensitive than the absolute cutoff value of the RSB $(300 \mu \mathrm{m})$ itself that influenced on the risk of ectasia the most.

\section{Role of PTA in eyes with suspicious topography}

Previous studies have shown that abnormal corneal topographic patterns are the most significant risk factor for postoperative ectasia. ${ }^{13,14}$ In a study specifically conducted on eyes with suspicious topography, Santhiago et $\mathrm{al}^{7}$ revealed that there remains a significant correlation between PTA values and ectasia risk after LASIK, even in eyes with suspicious corneal topography. Less tissue alteration, or a lower PTA value, was necessary to induce ectasia in eyes with more remarkable signs of topographic abnormality, and PTA provided better discriminative capabilities than RSB for all study populations. It should also be clear that these results do not indicate that it is safe to perform LASIK in eyes with suspicious topographic patterns simply by respecting a low PTA limit. In fact, these findings do corroborate that even subtle signs of abnormal topography are associated with ectasia after minimal tissue removal, and therefore, there is no safety limit under this setting.

\section{Relative contribution of FT and AD to PTA}

Despite representing a more individualized metric than CCT or RSB, PTA still has equally weighted components, such as FT and AD, that may not have equal importance. ${ }^{46,47}$ Since these variables affect the central cornea similarly but have significant differences in their relative alteration of peripheral corneal fibers, they may have different effects on ultimate biomechanical integrity based on anatomic differences in the anterior corneal stromal fiber interconnections.

Santhiago et al also conducted a specific study ${ }^{10}$ to investigate the relative contribution of FT and AD to PTA after
LASIK and to evaluate the importance of these differences in further differentiating between eyes that do and do not develop ectasia with normal preoperative topography. They found that LASIK flap had greater impact than AD; however, thicker flaps alone were insufficient to create ectasia unless coupled with greater ADs and thus high PTA values.

\section{Residual stromal bed}

The residual stromal bed (RSB) cutoff was proposed based on clinical observations, and although it has been a useful variable (in this case indirectly) informing about remaining load-bearing tissue after surgery, ${ }^{48}$ it definitely lacks preciseness due to the fact that it is not an individualized metric. As corneal tensile strength presents an inhomogeneous distribution throughout the central corneal stroma, ${ }^{43-45}$ with a progressive weakening, reaching the same value of RSB represents a significant different level of corneal impairment in eyes with different initial CCTs and is submitted to different ADs.

In $1998,{ }^{48}$ Seiler et al proposed the cutoff value of $250 \mu \mathrm{m}$ to avoid ectasia after LASIK, which was an important milestone at that time. It was a value that intuitively made sense, because it was similar to the values proposed by Barraquer for keratomileusis, ${ }^{49}$ and that presented an option that was not too conservative, still allowing moderate and sometimes even high-level of treatments.

However, there are some inconsistencies in the rationale for determining the value of $250 \mu \mathrm{m}$.

The authors ${ }^{48}$ cite a study published in $1980^{50}$ that would have found that the tangential elastic modulus of the keratoconic cornea is smaller by a factor of 2.1 compared to a normal cornea. The authors state, "assuming the biomechanical parameters are constant throughout corneal thickness, a normal corneal thickness could be reduced by this factor (2.1) before its elasticity is comparable to a keratoconus cornea", which was an assumption that would be a major flaw in the methodology that led to the conclusion of a cutoff of $250 \mu \mathrm{m}$, and this was even recognized by the authors when they state, "this assumption is rather optimistic since the deeper stroma appears to have less biomechanical strength compared to the anterior layers".

The biomechanical study published by Andreassen and Oxlund ${ }^{50}$ in 1980 (and cited by Seiler et al), although of high value, specially being conducted in the early 80 s, came to these conclusions based on the comparison of only six eyes with keratoconus obtained from penetrating keratoplasty with only seven measurements of normal eyes (the average of four patients from which the authors used both eyes and 
three other eyes of three different patients), also removed surgically. Besides the small sample size that is clearly not methodologically representative of a normal population, the measurements were not "in vivo" and the corneas presented a wide range of age (between 14 years and 31 years in the keratoconic group and between 14 years and 71 years in the normal group). Finally, to reach the value of $250 \mu \mathrm{m}$, Seiler et $\mathrm{al}^{48}$ assumed that an average normal cornea would have a value of $520 \mu \mathrm{m}$, which is itself a highly questionable value based on meta-analysis that suggested a thicker cornea as the normal mean value. ${ }^{51}$

It is therefore clear that the theoretical assumptions that pave the way for their recommendation of a cutoff value of $250 \mu \mathrm{m}$ are inaccurate in some areas and questionable in others. The biomechanical parameters are not constant throughout corneal thickness as the cohesive tensile strength is not uniform throughout the central corneal stroma with a progressive weakening in the posterior two-thirds; the 2.1 factor was based on a small sample size, not "in vivo" and with a wide range of age; and finally, the average cornea seems to be thicker than the values they use to calculate.

After that publication, the cutoff value of $250 \mu \mathrm{m}$ became one of the most utilized criteria to consider a candidate to be at higher risk for ectasia, and despite the inconsistencies just described, it should be regarded as an important contribution for that time. However, the role of RSB on ectasia risk is probably related to indirect measurements of the tissue removed, though obviously less accurate than the individualized measurement of PTA. Previous studies have shown that even eyes with normal topography and RSB within limits that is considered as low-risk developed ectasia, if presenting a high PTA value.

\section{Low preoperative corneal thickness}

Low preoperative corneal thickness alone has also been found to be a weak predictor of ectasia, since thin corneas, although less often, could still be within the normality range. ${ }^{51}$ The association with ectasia risk is related to the fact that keratoconic corneas tend to be thinner than normal corneas, ${ }^{37,42}$ and more importantly, as part of the equation that generates PTA, since the same ablation would mean a higher PTA in thinner corneas. ${ }^{9}$

Since keratoconic corneas are thinner than normal corneas, ${ }^{37,38,42,52-55}$ those with low preoperative corneal thickness may represent a sign of disease. However, although there seems to be truly thin corneas without detectable signs of disease, most of the cases already present topographic or tomographic signs of keratoconus. We have recently demonstrated that the prevalence of a preoperative CCT within the high-risk range $(<510 \mu \mathrm{m})$ in eyes with normal topography is significantly low. ${ }^{9}$ In normal eyes, the primary concern is not only the actual absolute corneal thickness but rather how that thickness combined with excimer laser ablation translates into postoperative corneal biomechanics, which is the primary concept of PTA. ${ }^{9}$

As compared to specific cutoff values of RSB or CCT, PTA likely provides a more individualized measure of biomechanical alteration because it considers the relationship between thickness, tissue altered through ablation and flap creation, and ultimate RSB thickness, all in the same metric and meaning different values for each individual. ${ }^{7,9-11}$

There are recent studies ${ }^{56-58}$ investigating the safety of LASIK in thin corneas that also presented normal topography and low PTA values, and even though the authors were not specifically using PTA at the time of their study, they were most likely within the safety limits for LASIK in this regard. However, as previously mentioned, we still believe that any eye with CCT values $<480 \mu \mathrm{m}$ should still be seen with caution, due to the prevalence of keratoconus in this group.

Pachymetry maps, thinnest point, and thickness profiles have also been demonstrated by different authors, ${ }^{31,36-38,53-55}$ which are helpful tools in differentiating normal and keratoconus eyes. Ambrósio et a $\mathrm{l}^{37,38}$ have reported a significantly faster progression of absolute stromal thickness from the thinnest point to the periphery in keratoconus eyes compared to that in the normal population. Reinstein et $\mathrm{al}^{36,53,54}$ have also shown a localized thinning of the epithelium at the center of a epithelial "donut pattern" and that the difference between the thinnest and thickest epithelia may be a helpful tool in detecting early stages of keratoconus and monitoring its progression over time.

\section{High myopia}

The situation with high myopia is similar to that with thin corneas in that they are both more prevalent among eyes with keratoconus $^{6}$ and when truly associated with the disease, commonly present together with clear signs of topographic or tomographic abnormalities.

Although in recent studies, the eyes in which ectasia occurred were significantly more myopic than controls, ${ }^{13,14}$ we have recently demonstrated that the isolated prevalence of a high myopia within the high-risk range (higher than 8 diopters) in eyes with normal topography is significantly low. ${ }^{9}$ The main explanation for this finding is that, ultimately, when not coupled with topographic or tomographic abnormality, high myopia represents $\mathrm{AD}$ and seems to be more 
important when correlated with the impairment on the corneal tissue as part of PTA equation. ${ }^{9}$

\section{Age as a risk factor}

In eyes with normal topography, age is most likely the main source of information about a patient's intrinsic biomechanical properties, ${ }^{2,8}$ and in fact, when matching for the topography status, eyes that developed ectasia tend to be younger than controls that have not developed ectasia. ${ }^{7,9,13,14,59}$ It could be partially explained by the fact that younger corneas theoretically present lower corneal cohesive tensile strength, which can shift over time ${ }^{43}$ and also considering keratoconus is a progressive disease, simply because young patients may have not yet developed the first detectable topographic signs. ${ }^{60,61}$ Young age is probably the most controversial risk factor, and therefore, probably, also the most overlooked one.

\section{A weighted screening system}

Randleman et $\mathrm{al}^{13,14,59}$ provided a valuable contribution to the refractive surgery field by identifying and determining the importance of risk factors through a stringent and validated scientific analysis that led to the development of a comprehensive screening approach: the ERSS. Their studies corroborated the relationship between abnormal corneal topography and ectasia as the most common and important high-risk sign.

They also provided scientific evidence that low RSB, low $\mathrm{CCT}$, high myopia, and young age are significant risk factors for the development of post-LASIK ectasia. Ectasia cases present, on average, significantly lower RSB thicknesses and thinner CCTs than controls. Understanding the relative importance of different factors may be challenging, and the unique feature of the ERSS, evaluating multiple risk factors simultaneously, is definitely a helpful tool in the screening strategy.

\section{Other risk factors}

Although there are no studies to scientifically validate the relationship between the history of eye rubbing and chronic trauma and the progression of ectasia, it does intuitively make sense and should be avoided. Besides the possible traumatic slippage between collagen fibrils, the main explanation is probably related to recruitment of inflammatory cells, enzyme activity under a higher temperature, and increase in intraocular pressure. ${ }^{62}$

Eye rubbing represents a different experience in each individual, meaning a different frequency and a different pressure on the cornea, which makes it challenging to determine its real impact on corneas with a variety of biomechanical intrinsic statuses. The possible association between keratoconus and atopic disease is also a potential bias in better understanding this relationship.

Unstable and suboptimal refractions with $<20 / 20$ best spectacle-corrected visual acuity and a family history of keratoconus may also be warning signs of undetectable ectatic disorders, increasing the risk of corneal ectasia after refractive surgery, and therefore, should be given consideration, especially in borderline candidates. ${ }^{6,63}$

Crosslinking has gained popularity through its proved efficacy on halting ectasia progression. ${ }^{64}$ As opposed to the thought that it could be used at the time of LASIK to avoid ectasia, we are of the opinion that this strategy should be further investigated as, in theory, crosslinking presents potent remodeling and flattening effects by potentially altering excimer laser predictability. ${ }^{65}$ Therefore, the best strategy currently available is not to add a concomitant procedure to avoid ectasia but carefully review and acknowledge the risk factors, as it is the purpose of this review.

\section{Conclusion}

The best strategy should take into consideration the reasonable analysis of each of the risk factors individually as well as their togetherness in a weighted fashion. Individually, Placido-disk corneal topography patterns seem to play a pivotal role as a surrogate of corneal strength and abnormal corneal topography remains to be the most important identifiable risk factor for ectasia.

Analysis of pachymetric and epithelial maps, obtained with different tomography technologies as well as computational strategies, available in the machines helping in the detection of early stages of keratoconus is additional and relevant information and therefore recommended to be incorporated into the daily screening process.

When topography is normal, PTA has been shown to be the most robust risk factor. PTA is not a screening metric, and therefore, a low PTA value does not mean that ectasia will not occur. It is, conversely, a tested and validated risk factor, which merely means a high PTA value is associated with a higher risk of ectasia after LASIK. The scientifically validated combined strategy ERSS has also proven to be very useful.

An extensive knowledge about all these risks is imperative to make the best decision for each patient, which ultimately makes the surgery safer. There are probably other associations we are not even aware of, and that is why research in this field should continue, investigating new potential risk factors, validating promising technologies, and refining combined strategies. 


\section{Disclosure}

Dr Santhiago is a consultant for Ziemer (Port, Switzerland) and Alcon (Fort Worth, TX, USA). Dr Smadja is a consultant for Ziemer (Port, Switzerland). The authors report no other conflicts of interest in this work.

\section{References}

1. Randleman JB. Evaluating risk factors for ectasia: what is the goal of assessing risk? J Refract Surg. 2010;26:236-237.

2. Dawson DG, Randleman JB, Grossniklaus HE. Corneal ectasia after excimer laser keratorefractive surgery: histopathology, ultrastructure, and pathophysiology. Ophthalmology. 2008;115:2181-2191.

3. Roy AS, Dupps WJ Jr. Effects of altered corneal stiffness on native and postoperative LASIK corneal biomechanical behavior: a whole-eye finite element analysis. $J$ Refract Surg. 2009;25:875-887.

4. Roberts CJ, Dupps WJ Jr. Biomechanics of corneal ectasia and biomechanical treatments. J Cataract Refract Surg. 2014;40:991-998.

5. Dupps WJ, Wilson SE. Biomechanics and wound healing in the cornea. Exp Eye Res. 2006;83(4):709-720.

6. Krachmer JH, Feder RS, Belin MW. Keratoconus and related noninflammatory corneal thinning disorders. Surv Ophthalmol. 1984; 28(4):293-322.

7. Santhiago MR, Smadja D, Wilson SE, Krueger RR, Monteiro ML, Randleman JB. Role of percent tissue altered on ectasia after LASIK in eyes with suspicious topography. $J$ Refract Surg. 2015;31:258-265.

8. Smadja D, Touboul D, Cohen A, et al. Detection of subclinical keratoconus using an automated decision tree classification. Am J Ophthalmol. 2013;156:237-246.

9. Santhiago MR, Smadja D, Gomes BF, et al. Association between the percent tissue altered and post-laser in situ keratomileusis ectasia in eyes with normal preoperative topography. Am J Ophthalmol. 2014;158:87-95.

10. Santhiago MR, Smadja D, Wilson SE, Randleman JB. Relative contribution of flap thickness and ablation depth to the percentage of tissue altered in ectasia after laser in situ keratomileusis. $J$ Cataract Refract Surg. 2015;41:2493-2500.

11. Santhiago MR, Wilson SE, Hallahan KM, et al. Changes in custom biomechanical variables after femtosecond laser in situ keratomileusis and photorefractive keratectomy for myopia. $J$ Cataract Refract Surg. 2014;40:918-928.

12. Santhiago MR, Kara-Junior N, Waring GO 4th. Microkeratome versus femtosecond flaps: accuracy and complications. Curr Opin Ophthalmol. 2014;25:270-274

13. Randleman JB, Russell B, Ward MA, Thompson KP, Stulting RD. Risk factors and prognosis for corneal ectasia after LASIK. Ophthalmology. 2003;110:267-275.

14. Randleman JB, Woodward M, Lynn MJ, Stulting RD. Risk assessment for ectasia after corneal refractive surgery. Ophthalmology. 2008;115: $37-50$.

15. Klyce SD, Wilson SE. Methods of analysis of corneal topography. Refract Corneal Surg. 1989;5:368-371.

16. Maeda N, Klyce S, Tano Y. Detection and classification of mild irregular astigmatism in patients with good visual acuity. Surv Ophthalmol. 1998; 43(1):53-58.

17. Maeda N, Klyce SD, Smolek M. Automated keratoconus screening with corneal topography analysis. Invest Ophthalmol Vis Sci. 1994;35: 2749-2757.

18. Wilson SE, Klyce SD. Screening for corneal topographic abnormalities before refractive surgery. Ophthalmology. 1994;101:147-152.

19. Wilson SE, Klyce SD, Husseini ZM. Standardized color-coded maps for corneal topography. Ophthalmology. 1993;100(11):1723-1727.

20. Wilson SE, Klyce SD. Quantitative descriptors of corneal topography. A clinical study. Arch Ophthalmol. 1991;109(3):349-353.

21. Rabinowitz YS, McDonnell PJ. Computer-assisted corneal topography in keratoconus. Refract Corneal Surg. 1989;5:400-408.
22. Piñero DP, Nieto JC, Lopez-Miguel A. Characterization of corneal structure in keratoconus. $J$ Cataract Refract Surg. 2012;38:2167-2183.

23. Randleman JB, Caster AI, Banning CS, Stulting RD. Corneal ectasia after photorefractive keratectomy. $J$ Cataract Refract Surg. 2006;32: 1395-1398.

24. Javadi MA, Mohammadpour M, Rabei HM. Keratectasia after LASIK but not after PRK in one patient. J Refract Surg. 2006;22:817-820.

25. Kymionis GD, Tsiklis N, Karp CL, Kalyvianaki M, Pallikaris AI. Unilateral corneal ectasia after laser in situ keratomileusis in a patient with uncomplicated photorefractive keratectomy in the fellow eye. J Cataract Refract Surg. 2007;33:859-861.

26. Hodge C, Lawless M, Sutton G. Keratectasia following LASIK in a patient with uncomplicated PRK in the fellow eye. $J$ Cataract Refract Surg. 2011;37:603-607.

27. Bühren J, Schäffeler T, Kohnen T. Preoperative topographic characteristics of eyes that developed postoperative LASIK keratectasia. J Refract Surg. 2013;29:540-549.

28. Rabinowitz YS, Rasheed K. KISA\% index: a quantitative videokeratography algorithm embodying minimal topographic criteria for diagnosing keratoconus. J Cataract Refract Surg. 1999;25(10):1327-1335.

29. Maeda N, Klyce SD, Smolek MK. Comparison of methods for detecting keratoconus using videokeratography. Arch Ophthalmol. 1995;113: $870-874$.

30. Mahmoud AM, Roberts CJ, Lembach RG, et al; CLEK Study Group. CLMI: the cone location and magnitude index. Cornea. 2008;27(4): 480-487.

31. Saad A, Gatinel D. Topographic and tomographic properties of forme fruste keratoconus corneas. Invest Ophthalmol Vis Sci. 2010;51(11): $5546-5555$.

32. Gilani F, Cortese M, Ambrósio RR, et al. Comprehensive anterior segment normal values generated by rotating Scheimpflug tomography. $J$ Cataract Refract Surg. 2013;39(11):1707-1712.

33. Steinberg J, Katz T, Lücke K, Frings A, Druchkiv V, Linke SJ. Screening for keratoconus with new dynamic biomechanical in vivo Scheimpflug analyses. Cornea. 2015;34(11):1404-1412.

34. Smadja D, Santhiago MR, Mello GR, Krueger RR, Colin J, Touboul D. Influence of the reference surface shape for discriminating between normal corneas, subclinical keratoconus, and keratoconus. J Refract Surg. 2013;29(4):274-281.

35. Rabinowitz YS, Li X, Canedo AL, Ambrósio R Jr, Bykhovskaya Y. Optical coherence tomography combined with videokeratography to differentiate mild keratoconus subtypes. J Refract Surg. 2014;30(2):80-87.

36. Reinstein DZ, Gobbe M, Archer TJ, Silverman RH, Coleman DJ Epithelial, stromal, and total corneal thickness in keratoconus: threedimensional display with artemis very-high frequency digital ultrasound. J Refract Surg. 2010;26(4):259-272.

37. Ambrósio R, Alonso RS, Luz A, Coca Velarde LG. Corneal-thickness spatial profile and corneal-volume distribution: tomographic indices to detect keratoconus. J Cataract Refract Surg. 2006;32(11):1851-1859.

38. Ambrósio R, Caiado AL, Guerra FP, et al. Novel pachymetric parameters based on corneal tomography for diagnosing keratoconus. $J$ Refract Surg. 2011;27(10):753-758.

39. Bühren J, Kook D, Yoon G, Kohnen T. Detection of subclinical keratoconus by using corneal anterior and posterior surface aberrations and thickness spatial profiles. Invest Ophthalmol Vis Sci. 2010;51:3424-3432.

40. Randleman JB, Dupps WJ, Santhiago MR, et al. Screening for keratoconus and related ectatic corneal disorders. Cornea. 2015;34:20-22.

41. Bae GH, Kim JR, Kim CH, Lim DH, Chung ES, Chung TY. Corneal topographic and tomographic analysis of fellow eyes in unilateral keratoconus patients using Pentacam. Am J Ophthalmol. 2014;157:103-109.

42. Ruiseñor Vázquez PR, Galletti JD, Minguez N, et al. Pentacam Scheimpflug tomography findings in topographically normal patients and subclinical keratoconus cases. Am J Ophthalmol. 2014;158(1):32-40.

43. Randleman JB, Dawson DG, Grossniklaus HE, McCarey BE, Edelhauser HF. Depth-dependent cohesive tensile strength in human donor corneas: implications for refractive surgery. J Refract Surg. 2008; 24:85-89. 
44. Reinstein DZ, Archer TJ, Randleman JB. Mathematical model to compare the relative tensile strength of the cornea after PRK, LASIK, and small incision lenticule extraction. J Refract Surg. 2013;29:454-460.

45. Scarcelli G, Kling S, Quijano E, Pineda R, Marcos S, Yun SH. Brillouin microscopy of collagen crosslinking: noncontact depth-dependent analysis of corneal elastic modulus. Invest Ophthalmol Vis Sci. 2013;54: 1418-1425.

46. Knox Cartwright NETJ, Jaycock PD, Marshall J. Effects of variation in depth and side cut angulations in LASIK and thin-flap LASIK using a femtosecond aser: a biomechanical study. J Refract Surg. 2012;28: 419-425.

47. Winkler M, Chai D, Kriling S, et al. Nonlinear optical macroscopic assessment of 3-D corneal collagen organization and axial biomechanics. Invest Ophthalmol Vis Sci. 2011;52:8818-8827.

48. Seiler T, Koufala K, Richter G. Iatrogenic keratectasia after laser in situ keratomileusis. J Refract Surg. 1998;14:312-317.

49. Barraquer J. Keratomileusis for myopia and aphakia. Ophthalmology. 1981;88(8):701-708.

50. Andreassen TTSA, Oxlund H. Biomechanical properties of keratoconus and normal corneas. Exp Eye Res. 1980;31(4):435-441.

51. Doughty MJ, Zaman ML. Human corneal thickness and its impact on intraocular pressure measures: a review and meta-analysis approach. Surv Ophthalmol. 2000;44:367-408.

52. Schlatter B, Beck M, Frueh BE, Tappeiner C, Zinkernagel M. Evaluation of scleral and corneal thickness in keratoconus patients. J Cataract Refract Surg. 2015;41(5):1073-1080.

53. Reinstein DZ, Archer TJ, Gobbe M, Silverman RH, Coleman DJ. Epithelial thickness in the normal cornea: three-dimensional display with Artemis very high-frequency digital ultrasound. J Refract Surg. 2008;24:571-581.

54. Reinstein DZ, Archer TJ, Gobbe M. Corneal epithelial thickness profile in the diagnosis of keratoconus. J Refract Surg. 2009;25:604-610.

55. Li YTO, Brass R, Weiss JL, Huang D. Corneal epithelial thickness mapping by Fourier-domain optical coherence tomography in normal and keratoconic eyes. Ophthalmology. 2012;119:2425-2433.
56. Djodeyre MR, Ortega-Usobiaga J, Beltran J, Baviera J. Long-term comparison of laser in situ keratomileusis versus laser surface ablation in corneas thinner than $470 \mu \mathrm{m}$. J Cataract Refract Surg. 2012;38(6): 1034-1042.

57. Kymionis GD, Bouzoukis D, Diakonis V, et al. Long-term results of thin corneas after refractive laser surgery. Am J Ophthalmol. 2007;144(2): $181-185$.

58. Tomita M, Watabe M, Mita M, Waring GO. Long-term observation and evaluation of femtosecond laser-assisted thin-flap laser in situ keratomileusis in eyes with thin corneas but normal topography. J Cataract Refract Surg. 2014;40(2):239-250.

59. Randleman JB, Trattler WB, Stulting RD. Validation of the ectasia risk score system for preoperative laser in situ keratomileusis screening. Am J Ophthalmol. 2008;145:813-818.

60. Soeters N, van der Valk R, Tahzib NG. Corneal cross-linking for treatment of progressive keratoconus in various age groups. J Refract Surg. 2014;30:454-460

61. Tuft SJ, Moodaley LC, Gregory WM, Davison CR, Buckley RJ. Prognostic factors for the progression of keratoconus. Ophthalmology. 1994;101: 439-447.

62. McMonnies CW. Mechanisms of rubbing-related corneal trauma in keratoconus. Cornea. 2009;28(6):607-615.

63. Rabinowitz YS, Garbus J, McDonnell PJ. Computer-assisted corneal topography in family members of patients with keratoconus. Arch Ophthalmol. 1990;108(3):365-371.

64. Randleman JB, Khandelwal SS, Hafezi F. Corneal cross-linking. Surv Ophthalmol. 2015;60(6):509-523.

65. Santhiago MR, Giacomin NT, Medeiros CS, Smadja D, Bechara SJ. Intense early flattening after corneal collagen cross-linking. J Refract Surg. 2015;31(6):419-422.
Clinical Ophthalmology

\section{Publish your work in this journal}

Clinical Ophthalmology is an international, peer-reviewed journal covering all subspecialties within ophthalmology. Key topics include: Optometry; Visual science; Pharmacology and drug therapy in eye diseases; Basic Sciences; Primary and Secondary eye care; Patient Safety and Quality of Care Improvements. This journal is indexed on Submit your manuscript here: http://www.dovepress.com/clinical-ophthalmology-journal

\section{Dovepress}

PubMed Central and CAS, and is the official journal of The Society of Clinical Ophthalmology (SCO). The manuscript management system is completely online and includes a very quick and fair peer-review system, which is all easy to use. Visit http://www.dovepress.com/ testimonials.php to read real quotes from published authors. 